\title{
Plant chemistry and aphid parasitoids (Hymenoptera: Braconidae): Imprinting and memory
}

\author{
Helmut F. van EMDEN ${ }^{1}$, ANDRew P. STORECK ${ }^{2}$, Sophia DOULOUMPAKA ${ }^{1}$, IOANNis ELEFTHERIANOS ${ }^{1}$, \\ GUY M. POPPY ${ }^{3}$ and WILF POWELL ${ }^{2}$
}

\author{
${ }^{1}$ School of Biological Sciences, University of Reading, Reading, Berkshire, RG6 6AJ, UK; e-mail: h.f.vanemden@reading.ac.uk \\ ${ }^{2}$ Plant and Invertebrate Ecology Department, Rothamsted Research, Harpenden, Hertfordshire, AL5 2JQ, UK; \\ e-mail: wilf.powell@bbsrc.ac.uk \\ ${ }^{3}$ School of Biological Sciences, University of Southampton, Southampton, UK. e-mail: gmp@soton.ac.uk
}

Key words. Braconidae, aphid parasitoid, Aphidius colemani, imprinting, memory, secondary compounds

\begin{abstract}
Emerging parasitoids of aphids encounter secondary plant chemistry from cues left by the mother parasitoid at oviposition and from the plant-feeding of the host aphid. In practice, however, it is secondary plant chemistry on the surface of the aphid mummy which influences parasitoid olfactory behaviour. Offspring of Aphidius colemani reared on Myzus persicae on artificial diet did not distinguish between the odours of bean and cabbage, but showed a clear preference for cabbage odour if sinigrin had been painted on the back of the mummy. Similarly Aphidius rhopalosiphi reared on Metopolophium dirhodum on wheat preferred the odour of wheat plants grown near tomato plants to odour of wheat alone if the wheat plants on which they had been reared had been exposed to the volatiles of nearby tomato plants. Aphidius rhopalosiphi reared on M. dirhodum, and removed from the mummy before emergence, showed a preference for the odour of a different wheat cultivar if they had contacted a mummy from that cultivar, and similar results were obtained with $A$. colemani naturally emerged from M. persicae mummies. Aphidius colemani emerged from mummies on one crucifer were allowed to contact in sequence (for $45 \mathrm{~min}$ each) mummies from two different crucifers. The number of attacks made in $10 \mathrm{~min}$ on $M$. persicae was always significantly higher when aphids were feeding on the same plant as the origin of the last mummy offered, or on the second plant if aphids feeding on the third plant were not included. Chilling emerged $A$. colemani for $24 \mathrm{~h}$ at $5^{\circ} \mathrm{C}$ appeared to erase the imprint of secondary plant chemistry, and they no longer showed host plant odour preferences in the olfactometer. When the parasitoids were chilled after three successive mummy experiences, memory of the last experience appeared at least temporarily erased and preference was then shown for the chemistry of the second experience.
\end{abstract}

\section{INTRODUCTION}

Aphidiine parasitoids of aphids show strong olfactory preferences for what is called the "host plant complex", the combination of their host aphid on leaves of the host plant (Wickremasinghe \& van Emden, 1992; Guerrieri et al., 1993; Du et al., 1996; Powell et al., 1998). However, there is often little or no attraction to the odour of the aphids in the absence of host plant material (Powell \& Zhang, 1983; Wickremasinghe \& van Emden, 1992). By contrast, attraction can often be shown to volatiles from uninfested host plant leaves (Powell \& Zhang, 1983; Powell \& Wright, 1992; Wickremasinghe \& van Emden, 1992).

Some of these olfactory responses appear to be innate (Storeck et al., 2000), using the term simply to denote behavioural responses that do not appear to have been learned, as discussed by Vet et al. (1995). More often they are conditioned in newly-emerged parasitoids during the process of emergence from the mummy, since no such responses are shown by parasitoids emerging from pupae excised from the mummy (van Emden et al., 1966; Storeck et al., 2000). However, Douloumpaka \& van Emden (2003) found that rearing parasitised aphids on artificial diet revealed a maternal cue for the odour of the plant on which the mother parasitoid had developed, but the offspring emerging from excised pupae showed no response to this cue. Douloumpaka \& van Emden (2003) hypothesised that this maternal cue was present in the silk cocoon around the parasitoid pupa, and this cocoon is left in the mummy when the pupa is removed. The parasitoid would, however, encounter the chemical cues in both the silk and the aphid cuticle while cutting its way out of the mummy during normal emergence (Fig. 1).

Although this acquisition of behavioural responses to olfactory stimuli encountered during adult eclosion and emergence from the mummy has been termed "emergence conditioning" (Storeck et al., 2000), the process could be regarded as a form of "imprinting" (see discussion of conditioning and imprinting processes by Hollis et al., 1991). Olfactory imprinting has been described with respect to the acquisition of olfactory preferences in a number of other organisms, including mosquitoes (McCall \& Eaton, 2001), spiders (Punzo, 2002) and nematodes (Remy \& Hobert, 2005).

This paper presents some evidence of where the cues in the aphid cuticle are located and their "over-riding" importance in conditioning early adult parasitoid olfactory responses. Additionally, work is described showing evidence of memory acquisition by the parasitoids, and how that memory may be temporarily erased by chilling, as previously demonstrated for a number of other insects, for example Drosophila melanogaster Meigen (Diptera: Drosophilidae) by Xia et al. (1999). 


\section{MATERIAL AND METHODS}

This paper was presented at a meeting on the "Ecology of Aphidophaga" held in Athens in September 2007, and therefore presents a mixture of published and as yet unpublished data carried out over several years and in several laboratories. The methods, apparatus and statistical analyses of data used therefore show more variation than would normally be found in a research paper.

Myzus persicae (Sulzer) and Metopolophium dirhodum (Walker) were the aphids (Hemiptera: Aphididae) used with Aphidius colemani Viereck and A. rhopalosiphi DeStefani Perez as the respective parasitoids (Hymenoptera: Braconidae). The cultures were maintained in a glasshouse (in the experiments relevant to Figs $1-3$ ) or in an $18^{\circ} \mathrm{C}$ growth room and on a variety of host plants as described for the different experiments.

Mummies were removed from the plants and kept in Petri dishes or tubes with moist cotton wool till the adult parasitoids emerged. Within $48 \mathrm{~h}$ of emergence the females were tested with a choice of two odours in a 2-chamber olfactometer (van Emden et al., 2002) or, in the case of the chilling experiments, a Y-tube olfactometer. Parasitoids which did not respond were omitted from the analysis (details of the analysis are given in the Figure legends).

\section{Painting secondary plant chemistry on the mummy}

This experiment compared the importance of the chemical cue left by the mother parasitoid at oviposition (Douloumpaka \& van Emden, 2003) with that in or on the aphid cuticle. Aphidius colemani were obtained from M. persicae reared on Brussels sprout var. "Bedford Winter Harvest" and allowed to parasitise M. persicae on artificial diet (Douglas \& van Emden, 2007). Mummies were removed from the diet and, about $48 \mathrm{~h}$ before parasitoids were due to emerge, some of the mummies were painted on the back with a $0.1 \%$ sinigrin solution. Sinigrin is a secondary compound characteristic of many brassicas. The unpainted mummies would contain only the weak maternal cue derived from the host plant of the mother parasitoid (Douloumpaka \& van Emden, 2003); the sinigrin would add a strong aphid cuticle cue. Female parasitoids emerging from the two types of mummies were tested with the odours of leaves of cabbage (var. "F1 Hispi") and a broad bean (var. "The Sutton").

There were 6 replicates of groups of $12-15$ parasitoids.

\section{Presence of other plant volatiles in the environment}

This experiment is described in detail by van Emden et al. (2002).

Eight cages ( $45 \mathrm{~cm}$ cubes) were set up with 10 adult $M$. dirhodum on each of 6-8 wheat (var. "Maris Huntsman") plants in a single pot in the centre of the cage. Four of the cages also had a small potted tomato (var. "Moneymaker") plant placed in each corner, well away from the wheat. After one week, six mated female $A$. rhopalosiphi were released into each cage and removed after $24 \mathrm{~h}$. After another 7 days, i.e. shortly before mummification, the tomato plants were exchanged between the cages. Thus the wheat and aphids in one set of cages were exposed to the odour of tomato plants before the parasitised aphids mummified, while tomato plant odour was only present in the other cages after the parasitised aphids had stopped feeding.

When the parasitoid pupae showed as dark patches (1-2 days before emergence), mummies were removed from the plants and the female olfactory preferences tested for two kinds of wheat leaves, those from wheat grown alone and those from wheat grown in the proximity of tomatoes. For each of the two cage treatments there were 7 replicates of groups of 10-12 parasitoids.

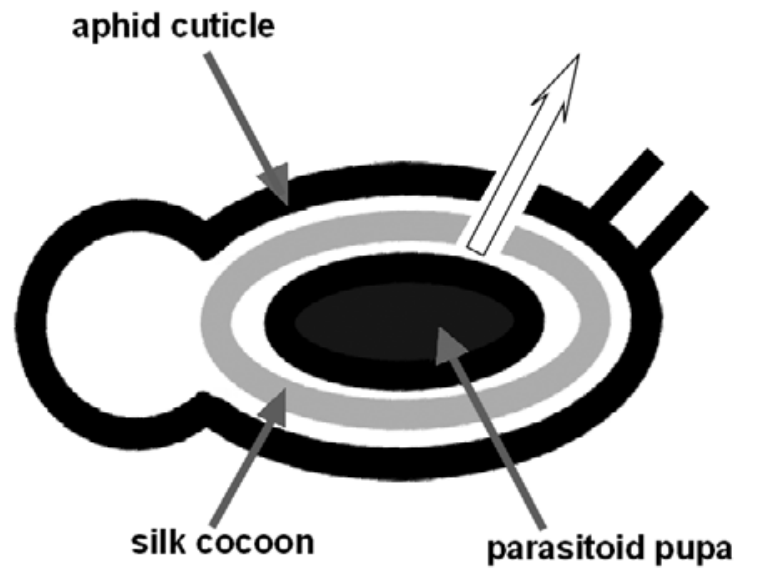

Fig. 1. The layers through which an adult parasitoid has to cut to emerge from the mummy.

Does imprinting require passage through the silk and cuticle, or can it occur just by contact with the mummy surface?

The previous two experiments gave a strong indication that imprinting can occur during contact with the mummy surface alone, but chemicals there will also diffuse downwards through the cuticle and be encountered below the surface during the emergence process.

The cutting out from the mummy of the parasitoid during emergence can be eliminated by excising the parasitoid pupa, so this experiment (van Emden et al., 2002) offered parasitoids emerged from excised pupae a surface contact with mummies from a different plant.

Aphidius rhopalosiphi were reared for two generations on $M$. dirhodum on two wheat cultivars, "Maris Huntsman" and "Rapier". Parasitoid pupae were excised from mummies harvested from both varieties and emerged females were tested with the odours of leaves of the two wheat varieties after $30 \mathrm{~min}$ contact with a mummy from the alternative variety. There were 12 replicates of groups of $10-12$ parasitoids per source wheat variety.

Is imprinting over-ridden by a second contact with another mummy from a different plant source?

Even after imprinting has occurred during natural emergence from a mummy, this might be over-ridden by a further experience with a different olfactory cue on the surface of a different mummy.

This possibility was tested with $A$. colemani emerging from mummies of M. persicae reared on oilseed rape or Chinese cabbage and then given a $1 \mathrm{~h}$ post-emergence experience of an empty mummy from the alternative plant. $24 \mathrm{~h}$ later they were tested in a Y-tube olfactometer presenting odours of M. persicae infested leaves of the two host plants. For each source brassica there were 10 replicates of groups of 10 parasitoids.

\section{The olfactory response of parasitoids at the end of a} 3-mummy sequence of experiences

The results so far suggested it would be worth extending the 2-mummy sequence to 3-mummies with a further mummy from yet another plant source.

Female A. colemani emerged from M. persicae mummies (1st experience) were allowed to contact mummies from a different plant for $45 \mathrm{~min}$ (2nd experience) and then for a further $45 \mathrm{~min}$ a mummy from yet another plant (3rd experience). The two 


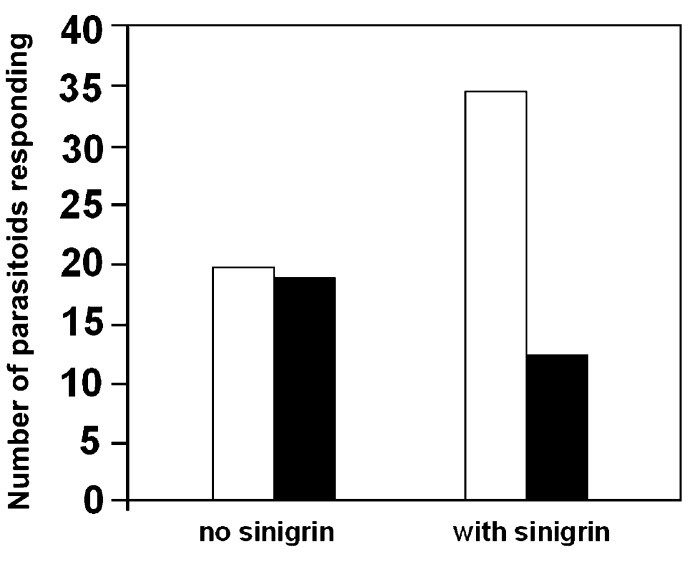

Fig. 2. Numbers of female Aphidius colemani responding to the odours of cabbage (white) and broad bean (black) when emerging from Myzus persicae reared on artificial diet with and without sinigrin painted on the mummy (6 replicates of 12-15 parasitoids per replicate). For mummies without sinigrin $\chi^{2}$ (1.d.f. $)=0.02 \mathrm{~ns}$, heterogeneity $\chi^{2}(5$ d.f. $)=1.1 \mathrm{~ns}$; with sinigrin $\chi^{2}(1$. d.f. $)=10.5^{* *}$, heterogeneity $\chi^{2}(5$ d.f. $)=1.5 \mathrm{~ns}$.

sequences of experiences run were oilseed rape - kale - Chinese cabbage and Chinese cabbage - oilseed rape - kale.

Olfactory imprinting was assessed by releasing individual females into Petri dishes with aphid-infested leaves, and recording the number of attacks on aphids that the parasitoids made in the first $10 \mathrm{~min}$. Each Petri dish compared infested leaf material from two of the three plants involved in the sequence of experiences, and there were 10 replicates per leaf material comparison.

\section{The effect of chilling on parasitoid olfactory responses} imprinted at emergence from the mummy

The work on Drosophila by Xia et al. (1999) mentioned in the introduction to this paper suggested that the olfactory imprinting aphid parasitoids receive on emergence from the mummy might be destroyed or suppressed by a period of chilling. This experiment was motivated purely by scientific curiosity, but also has potential practical importance in relation to the mass rearing of biological control agents (see Discussion).

Aphidius colemani emerged from M. persicae on kale were tested in a Y-tube olfactometer for their choice of two contrasting odour streams: that from $M$. persicae feeding on kale and that from another aphid, Sitobion avenae (Fabricius), feeding on barley. The olfactometer tests were carried out the day after emergence, with some of the emerged parasitoids chilled at $5^{\circ} \mathrm{C}$ for $24 \mathrm{~h}$ while the others were held at $18^{\circ} \mathrm{C}$. There were 10 replicates of groups of 10 parasitoids.

The effect of chilling on imprinting of parasitoid olfactory responses with a sequence of mummy experiences

The same $24 \mathrm{~h}$ chilling and no-chilling treatments were applied to A. colemani at the end of the same sequences of $3 \mathrm{M}$. persicae mummy experiences as used previously: i.e. oilseed rape $($ origin $=1$ st experience $)-$ kale $(2$ nd experience $)-$ Chinese cabbage (3rd experience) and Chinese cabbage (origin $=1 \mathrm{st}$ experience) - oilseed rape (2nd experience) - kale (3rd experience). The olfactometer tests compared odours from infested leaves reflecting the 1 st versus the 2 nd experience and the 2 nd versus the 3rd. Each sequence of experiences was replicated 10 times with groups of 10 parasitoids.
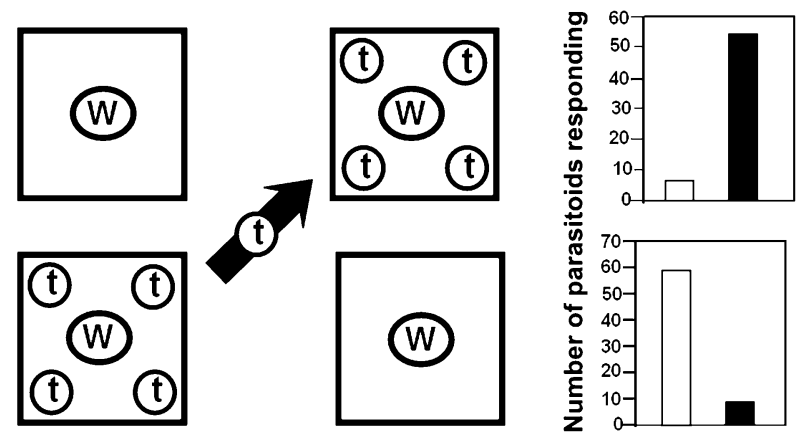

Fig. 3. Numbers of female Aphidius rhopalosiphi emerging from Metopolophium dirhodum and responding to odours of wheat leaves either grown alone (white) or near tomato plants (black) following two experimental sequences with tomato plants present in the cages at different times ( 7 replicates per sequence of 10-12 parasitoids per replicate). For parasitoids in upper sequence $\chi^{2}$ (1.d.f.) $=37.2^{* * *}$, heterogeneity $\chi^{2}(6$ d.f. $)=$ $5.2 \mathrm{~ns}$; lower sequence $\chi^{2}(1$ d.f. $)=35.8^{* * *}$, heterogeneity $\chi^{2}(6$ d.f.) $=4.8 \mathrm{~ns}$ (from data of van Emden et al., 2002).

\section{Analysis of data}

Experiments were analysed either with a $\chi^{2}$ test or a 2-way analysis of variance as indicated in the legend to the relevant Figure.

$\chi^{2}$ for 1 d.f. was calculated for the two odours being compared, but with the consistency of any significant preference checked by calculating the heterogeneity $\chi^{2}$ of that preference between the individual replicates.

Like the $\chi^{2}$ tests, the 2-way analyses of variance tested the significance of the $\mathrm{F}$ ratio for 1 d.f. for the two treatments being compared against the d.f. of the residual mean square which, similarly to a heterogeneity $\chi^{2}$, measures the consistency of the treatment effect between the individual replicates.

\section{RESULTS}

\section{Painting secondary plant chemistry on the mummy}

Parasitoids emerging from mummies that had not been painted with sinigrin showed no preference for cabbage over broad bean in spite of the mother having left a chemical cue for a brassica as demonstrated by Douloumpaka \& van Emden (2003). Painting sinigrin on the mummy changed this lack of preference to a strong preference for the odour of cabbage $(\mathrm{P}<0.01)$.

\section{Presence of other plant volatiles in the environment}

The results were clear cut (Fig. 3). The parasitoids responded positively to the odours the mummy had experienced in the second phase of the experiment $(\mathrm{P}<$ $0.001)$. If tomato plants were present in the cage during the mummy stage of parasitisation, the emerging parasitoids showed a preference for the odour of wheat leaves "contaminated" with tomato volatiles. These volatiles appear to be absorbed by plant and aphid cuticles. Similarly, where tomato plants were removed for the second period of the experiment, the tomato volatiles were lost and the emerging parasitoids showed a preference for the 


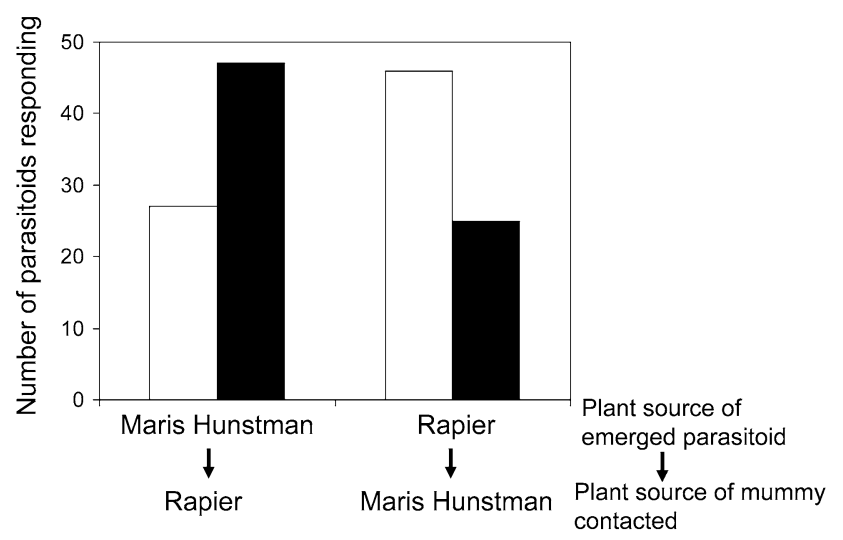

Fig. 4. Numbers of female Aphidius rhopalosiphi emerging from pupae excised from Metopolophium dirhodum mummies and responding to odours of leaves of "Maris Huntsman" (white) or "Rapier" wheat (black) following contact with a $M$. dirhodum mummy from the alternative variety (12 replicates of 5-12 parasitoids per replicate). For parasitoids reared on Maris Huntsman $\chi^{2}(1$. d.f. $)=5.4^{*}$, heterogeneity $\chi^{2}(11$ d.f. $)=4.4 \mathrm{~ns}$; for parasitoids reared on Rapier $\chi^{2}$ (1.d.f.) $=6.2^{*}$, heterogeneity $\chi^{2}(11$ d.f.) $=6.5 \mathrm{~ns}$ (from data of van Emden et al., 2002).

odour of "uncontaminated" wheat leaves. So in both sequences the parasitoids were imprinted as a result of exposure to the chemistry of the mummy cuticle at emergence rather than earlier.

Does imprinting require passage through the silk and cuticle, or can it occur just by contact with the mummy surface?

Although the proportion of non-responding parasitoids was rather high (26-27\%), the parasitoids showed a significant preference $(\mathrm{P}<0.05$ for each of the two treatments) for the "alien" mummy they had contacted after emergence (Fig. 4). Clearly olfactory imprinting of the parasitoids could occur by mere surface contact with a mummy.

\section{Is imprinting over-ridden by a second contact with another mummy from a different plant source?}

The results (Fig. 5) were essentially identical to the previous experiment with parasitoids emerged from excised pupae. It was the post-emergence contact with a mummy from a different plant that determined the olfactory response shown by the parasitoids $(\mathrm{P}<0.001)$.

\section{The olfactory response of parasitoids at the end of a 3-mummy sequence of experiences}

Both sequences of mummy experiences gave the same result (Fig. 6). In paired comparisons, aphids on leaf material reflecting the $3 \mathrm{rd}$ (last) experience received significantly $(\mathrm{P}<0.001)$ more attacks than aphids on leaf material from the 1 st and 2 nd experience plants. The important result, however, was found when the 2 nd and 1 st experiences were compared. Then, in both sequences, aphids on leaf material representing the now more recent experience (2nd) received more attacks than aphids on leaves representing the earlier 1 st experience.

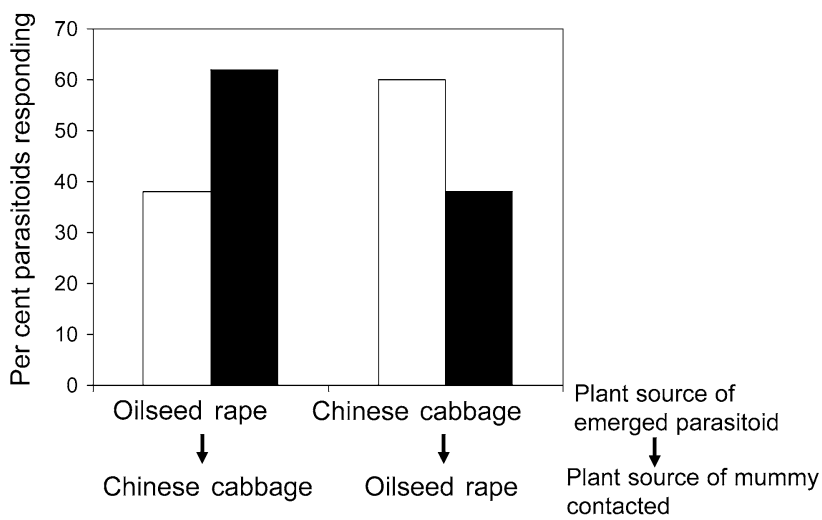

Fig. 5. Numbers of Aphidius colemani (sexes not separated) emerging from Myzus persicae mummies from oilseed rape and Chinese cabbage and responding to odours of aphid infested leaves of these plants (white, oilseed rape; black, Chinese cabbage) following contact with an empty $M$. persicae mummy from the alternative plant (10 replicates of 10 parasitoids per replicate). Results analysed by analysis of variance; $\mathrm{P}<0.001$ for difference between the two columns in both histograms.

The effect of chilling on parasitoid olfactory responses imprinted at emergence from the mummy

As expected from other results, the control (not chilled) parasitoids emerged from mummies from kale showed strong preference for odour of the plant-host complex on kale over that of the barley complex $(\mathrm{P}<0.001)$. However, this preference was completely eradicated by the 24 h of chilling (Fig. 7).

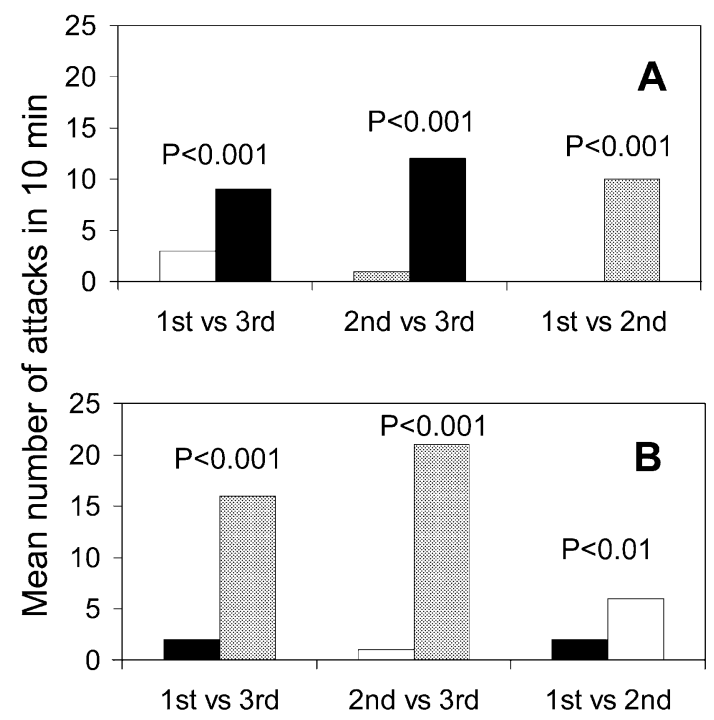

Fig. 6. Numbers of attacks in $10 \mathrm{~min}$ by single female Aphidius colemani on Myzus persicae in arenas with aphidinfested leaves from pairs of plants (white, oilseed rape; black, Chinese cabbage; grey, kale). A: parasitoids emerged from mummies from oilseed rape (1st experience), then allowed to contact - each time for 45 min - a mummy from kale (2nd experience) and then a mummy from Chinese cabbage (3rd experience). B: Chinese cabbage (origin $=1$ st experience), oilseed rape (2nd experience and kale (3rd experience). Results of paired comparisons (each with 10 replicates) analysed by analysis of variance; significant differences as indicated on Figure. 


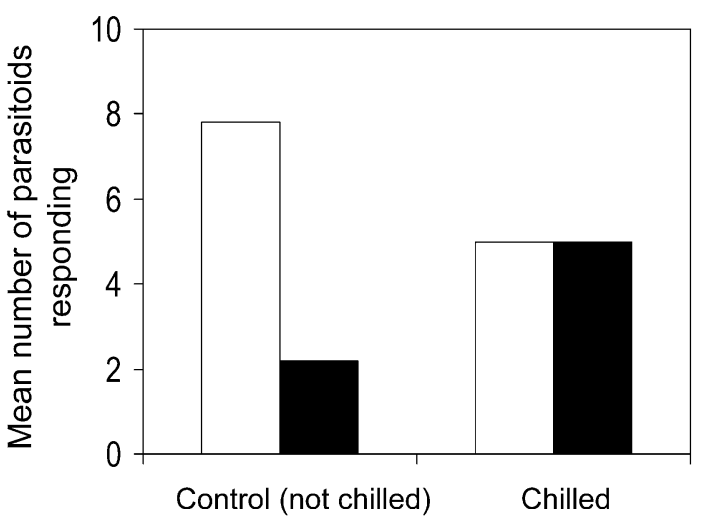

Fig. 7. Numbers of Aphidius colemani (sexes not separated) emerging from Myzus persicae mummies from kale and responding to odours of $M$. persicae infested leaves of kale (white) or barley infested with the aphid Sitobion avenae (black). One (control) group of parasitoids was kept for $24 \mathrm{~h}$ at $18^{\circ} \mathrm{C}$ before testing; another group was chilled for $24 \mathrm{~h}$ at $5^{\circ} \mathrm{C}$. Results analysed by analysis of variance; $\mathrm{P}<0.001$ for difference between the two columns in the unchilled treatment, there is no difference between the two columns in the chilled treatment.

\section{The effect of chilling on imprinting of parasitoid olfactory responses with a sequence of mummy experiences}

Emerged parasitoids held at $18^{\circ} \mathrm{C}$ (control) for $24 \mathrm{~h}$ showed the expected responses of preference $(\mathrm{P}<0.05$ or $<0.001)$ for odours reflecting the latest of the three experiences offered in each comparison (i.e. 2nd preferred over 1 st and 3rd preferred over 2nd).

The effect of chilling the parasitoids at $5^{\circ} \mathrm{C}$ for $24 \mathrm{~h}$ on the olfactory preferences of the parasitoids with the same odour comparisons is shown by comparing the left and right column pairs of each set of four histograms in Fig. 8.

In the first sequence, chilling appeared to remove any preference for the odour reflecting the 2nd experience compared with the $1 \mathrm{st}$, but the main result of this experiment is seen in the effect of chilling on the comparison of odours reflecting the 2 nd versus the 3 rd experience. Preference for the last (3rd) experience now disappeared and was replaced by a preference reflecting the earlier 2 nd experience.

\section{DISCUSSION}

In the last twenty years it has become obvious that there are many sources of chemical information which may condition the olfactory behaviour of adult aphid parasitoids. Some positive responses to compounds such as general green leaf volatiles (P. Vamvatsikos, unpubl. results) or compounds more specific to a plant species (Storeck et al., 2000; Storeck, 2003) may occur regardless of adult parasitoid olfactory experiences, but most appear to become acquired as a result of experience of the parasitoids. Cues to the plant chemistry experienced by the mother are left with her offspring at oviposition. Under the unnatural circumstances of a parasitoid developing in an aphid on artificial diet (after parasitisation on leaf
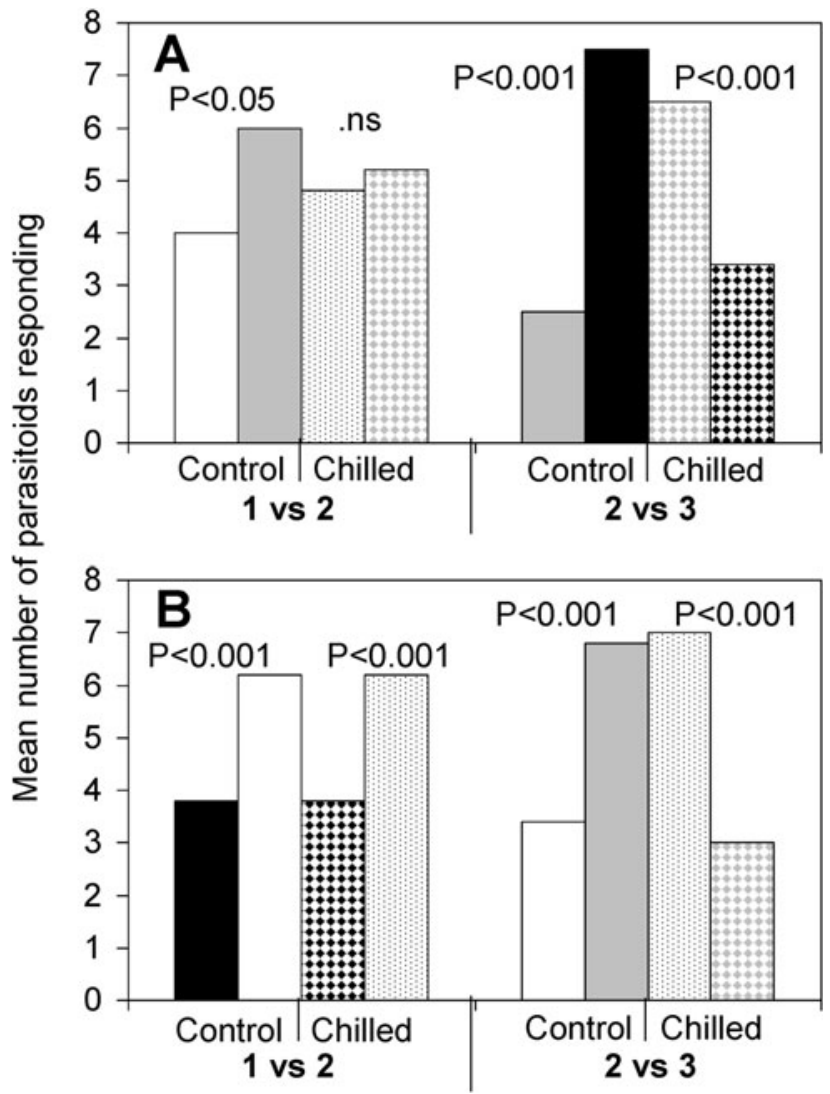

Fig. 8. Numbers of Aphidius colemani (sexes not separated) emerging from Myzus persicae mummies from kale and responding to odours of $M$. persicae infested leaves from pairs of plants (white, oilseed rape; black, Chinese cabbage; grey, kale). A: parasitoids emerged from mummies from oilseed rape (1st experience), then allowed to contact - each time for $45 \mathrm{~min}$ - a mummy from kale (2nd experience) and then a mummy from Chinese cabbage (3rd experience). B: Chinese cabbage (origin $=1$ st experience), oilseed rape (2nd experience and kale (3rd experience) (10 replicates). Each set of four histograms shows data from the control treatments in plain columns on the left and data from the chilled treatments in speckled columns on the right. Results analysed by analysis of variance; significant differences between control and chilled treatments as indicated on the Figure. Means are of 10 replicates, each with 10 parasitoids.

material), this maternal cue may either re-inforce or cancel out the cue acquired by the host aphid during the $48 \mathrm{~h}$ of plant-feeding while exposed to parasitisation (Douloumpaka \& van Emden, 2003). Gutiérrez-Ibáñez et al. (2007) suggest that the parasitoid larva may also learn cues from the leaf surface at a pre-imaginal stage while attaching the host aphid to the leaf with silk through a slot cut in the ventral surface of the host, but this is ruled out when the parasitised aphids complete their development on artificial diet. The aphid haemolymph, with which the parasitoid larva is in continual contact, presumably also contains the secondary chemistry of the host plant, and it is assumed that this is the source of the secondary chemistry in the aphid cuticle which the parasitoid contacts at emergence. 
It has been suggested that this process of olfactory imprinting through contact with plant chemistry present on the mummy at the time of adult parasitoid emergence supports the "chemical legacy hypothesis" proposed by Corbet (1985); host plant chemicals acquired during the larval stages of development are carried over on (and in) the cuticle of the dead host and are subsequently encountered by the adult parasitoid (Storeck et al., 2000). Olfactory imprinting does not appear to occur if the eclosing adult parasitoid is denied contact with the mummy and so there is no evidence that olfactory responses are determined during pre-imaginal stages of development, providing no support for Hopkins host-selection principle (Hopkins, 1917). However, determination of host preference through early adult experience, often during or shortly after emergence, has been termed the neoHopkins principle (Jaenike, 1983). Nevertheless, there is some evidence in support of the original Hopkins hostselection principle, in which preferences are determined during early developmental stages through learning processes, for a parasitoid (Gandolfi et al., 2003) and for other insects (Isingrini et al., 1985; Rietdorf \& Steidle, 2002).

The aphid/mummy cuticle, the silk cocoon and the pupal cuticle of the parasitoid are all in contact with each other. The demonstration by van Emden et al. (2002) that mummies on wheat and the wheat leaves themselves absorb volatiles from nearby tomato plants raises the important question as to how far chemicals diffuse between these three layers. It seems likely that they would do so, in which case it becomes hard to separate pre- and post-imaginal experiences by experimental procedures such as excision of the parasitoid pupa from the aphid mummy before emergence.

What the work described in this paper clearly shows, however, is that the normal situation will be for olfactory imprinting of the parasitoid to occur during post-imaginal experience of the surface of the mummy, whatever other external and internal cues are experienced elsewhere. That this alone will determine the parasitoid's olfactory behaviour is clear from the results reported here with sinigrin painted on the back of $A$. colemani mummies of $M$. persicae reared on artificial diet, the reactions of $A$. rhopalosiphi to the mummy cuticle in the absence and presence of nearby tomatoes and the conditioning of $A$. colemani to different chemistry when given experience of a second mummy, a sequence of mummies or a mummy from a different plant contacted by the parasitoid (in this case $A$. rhopalosiphi) emerging from an excised pupa. It is interesting that parasitoids seem able to "translate" a contact stimulus with a non-volatile compound such as sinigrin (painted on the back of the mummy) into relevant volatiles (allylisothiocyanates) in air entrained over the host plant in an olfactometer.

Thus, even after emerging from its own mummy, $A$. colemani changes its olfactory or attack preferences if it is allowed to contact (for $45 \mathrm{~min}$ in our experiments) the surface of a mummy from a different plant, even if the two plants involved are both brassicas (oilseed rape and Chinese cabbage in our experiments). These two bras- sicas are perhaps unusually different in their secondary chemistry in that Harisprasad (2003) was unable to detect sinigrin in Chinese cabbage, but similar changes in the behaviour of $A$. colemani were shown with the chemically more similar oilseed rape and kale in the 3-mummy experience experiments.

In these latter experiments, $A$. colemani showed olfactory preferences for the chemistry of the last of three mummies they had contacted, and never for the first mummy from which they had emerged. With mummies from oilseed rape, kale and Chinese cabbage presented in two different sequences, $A$. colemani consistently responded to the chemistry of the last-encountered of any two experiences presented to them. Thus they attacked more aphids in $10 \mathrm{~min}$ if these were presented on a leaf representing the final of the three experiences when compared with either the 1 st or 2 nd, and the 2 nd when compared only with the 1 st. This last result seems to suggest that experiences can be retained in sequence in memory. A very similar result was obtained when the eucoilid parasitoid Leptopilina boulardi (Barbotin, Carton \& Kellner-Pillaut) (Hymenoptera: Eucoilidae) was exposed to three different odours, provided sequentially, which were associated with oviposition experience. When given a choice, the parasitoids preferred the last experienced odour but, if the choice was between the first and second odours, they preferred the second (Kaiser \& De Jong, 1993).

The literature on Drosophila (Xia et al., 1999) suggested another possibility for moving the response to chemical experience one step back in a sequence by chilling the emerged insects after they had been conditioned to a chemical experience. To test whether it was worth developing such work, A. colemani were reared on $M$. persicae on kale and conditioned by allowing them to emerge naturally from the mummies; some were kept at $5^{\circ} \mathrm{C}$ and the others at $18^{\circ} \mathrm{C}$. After $24 \mathrm{~h}$ at $5^{\circ} \mathrm{C}$, the chilled parasitoids had lost their conditioned response, and showed no olfactory preference for the odour of $M$. persicae on kale over that of a host plant complex not previously experienced $-S$. avenae on barley.

This loss of memory was then followed-up by repeating the two earlier 3-mummy experience sequences, this time again chilling some of the parasitoids at the end of both sequences.

The olfactory responses of the parasitoids which did not receive the chilling treatment were essentially the same as their attack response in the previous experiment with 3 -mummy sequences in that the chemistry of the 2 nd experience was preferred over the 1 st and the 3 rd over the 2nd.

By contrast, the chilled parasitoids no longer preferred the chemistry of the last (3rd) experience over the 2 nd. Indeed, in this comparison the preference of the parasitoids that had not been chilled was reversed and chemistry of the 2 nd experience was now clearly preferred by the chilled parasitoids over that of the $3 \mathrm{rd}$. The preference for the chemistry of the 2 nd experience over the 1 st was 
retained, though for unknown reasons this difference was not shown in the first sequence.

It seems possible that, as with Drosophila (Xia et al., 1999), the last experience is retained in a shorter-term memory than a previous experience, and that it is this memory which is disrupted by chilling. In Drosophila this disruption was temporary, and similarly with $A$. colemani Storeck (2003) found that a shorter but cooler chilling experience $\left(1^{\circ} \mathrm{C}\right.$ for $\left.15 \mathrm{~min}\right)$ disrupted the memory for only about $2 \mathrm{~h}$. Understanding the effects of chilling on olfactory memory in parasitoids could be important in the context of mass rearing of parasitoids for biological control of insect pests in agriculture and horticulture, where cold conditions may be used for short term storage.

Most of the work reported here involved the generalist parasitoid $A$. colemani. It is possible that more specialist parasitoids show different behaviour, though work reported here with the more oligophagous $A$. rhopalosiphi has given similar results.

\section{REFERENCES}

CoRBET S.A. 1985: Insect chemosensory responses: a chemical legacy hypothesis. Ecol. Entomol. 10: 143-153.

Douglas A.E. \& van EMden H.F. 2007: Nutrition and symbiosis. In van Emden H.F. \& Harrington R. (eds): Aphids as Crop Pests. CABI, Wallingford, pp. 115-151.

DouloumpaKa S. \& van EmDen H.F. 2003: A maternal influence on the conditioning to plant cues of Aphidius colemani Viereck, parasitizing the aphid Myzus persicae Sulzer. Physiol. Entomol. 28: 108-113.

Du Y., Poppy G.M., Powell W., Pickett J.A., Wadhams L.J. \& Woodcock C. 1996: Identification of semiochemicals released during feeding that attract Aphidius ervi. J. Chem. Ecol. 24: 1355-1368.

van Emden H.F., Sponagl B., Wagner E., Baker T., Ganguly S. \& Douloumpaka S. 1996: Hopkins' "host selection principle", another nail in its coffin. Physiol. Entomol. 21: 325-328.

van Emden H.F., Eleftherianos I., Rose J., DouloumpaKa S. \& Pettersson J. 2002: Aphid parasitoids detect that an alien plant was present nearby during their development. Physiol. Entomol. 27: 199-205.

Gandolfi M., Mattiacci L. \& Dorn S. 2003: Preimaginal learning determines adult response to chemical stimuli in a parasitic wasp. Proc. R. Soc. Lond. (B) 270: 2623-2629.

Guerrieri E., Pennacchio F. \& Tremblay E. 1993: Flight behaviour of the aphid parasitoid Aphidius ervi (Hymenoptera: Braconidae) in response to plant and host volatiles. Eur. J. Entomol. 90: 415-421.

GutiérRez-Ibáñ̃z C., Villagra C.A. \& Niemeyer H.M. 2007: Pre-pupation behaviour of the aphid parasitoid Aphidius ervi (Haliday) and its consequences for pre-imaginal learning. Naturwissenschaften 94: 595-600.

Hariprasad K.V. 2003: Effect of Plant Resistance in Glasshouse and Field Grown Brassicas to Plutella xylostella and its Larval Endoparasitoid Cotesia plutellae, with Special Refer- ence to Insecticide Tolerance. $\mathrm{PhD}$ Thesis, University of Reading.

Hollis K.L., Ten Cate C. \& Bateson P. 1991: Stimulus representation: a subprocess of imprinting and conditioning. $J$. Comp. Psychol. 105: 307-317.

Hopkins A.D. 1917: A discussion of H.G. Hewitt's paper on "Insect behaviour". J. Econ. Entomol. 10: 92-93.

IsINGRINI M., LENOIR A. \& JAISSON P. 1985: Preimaginal learning as a basis of colony-brood recognition in the ant Cataglyphis cursor. Proc. Natl. Acad. Sci. 82: 8545-8547.

JAENIKE J. 1983: Induction of host preference in Drosophila melanogaster. Oecologia 58: 320-325.

KaISER L. \& De Jong R. 1993: Multi-odour memory influenced by learning order. Behav. Process. 30: 175-184.

McCall P.J. \& Eaton G. 2001: Olfactory memory in the mosquito Culex quinquefasciatus. Med. Vet. Entomol. 15: 197-203.

Powell W. \& Zhang Z.-L. 1983: The reactions of two cereal aphid parasitoids, Aphidius uzbekistanicus and A. ervi to host aphids and their food-plants. Physiol. Entomol. 8: 439-443.

Powell W. \& Wright A.F. 1992: The influence of host food plants on host recognition by four aphidiine parasitoids (Hymenoptera: Braconidae). Bull. Entomol. Res. 81: 449-453.

Powell W., Pennacchio F., Poppy G.M. \& Tremblay E. 1998: Strategies involved in the location of hosts by the parasitoid Aphidius ervi Haliday (Hymenoptera: Braconidae: Aphidiinae). Biol. Control 11: 104-112.

Punzo F. 2002: Food imprinting and subsequent prey preference in the lynx spider, Oxyopes salticus (Araneae: Oxyopidae). Behav. Process. 58: 177-181.

Remy J.-J. \& Hobert O. 2005: An interneural chemoreceptor required for olfactory imprinting in C. elegans. Science 309: 787-790.

Rietdorf K. \& Steidle J.L.M. 2002: Was Hopkins right? Influence of larval and early adult experience on the olfactory response in the granary weevil Sitophilus granarius (Coleoptera, Curculionidae). Physiol. Entomol. 27: 223-227.

Storeck A.P. 2003: Learning and Memory in the Aphid Parasitoid Aphidius colemani Viereck (Hymenoptera: Braconidae). $\mathrm{PhD}$ Thesis, University of Reading.

Storeck A., Poppy G.M., van Emden H.F. \& Powell W. 2000: The role of plant chemical cues in determining host preference in the generalist aphid parasitoid Aphidius colemani. Entomol. Exp. Appl. 17: 297-304.

Vet L.E.M., Lewis W.J. \& CARdÉ R.T. 1995: Parasitoid foraging and learning. In Cardé R.T. \& Bell W.J. (eds): Chemical Ecology of Insects. Vol. 2. Chapman \& Hall, New York, pp. 65-101.

Wickremasinghe M.G.V. \& VAN EMden H.F. 1992: Reactions of adult female parasitoids, particularly Aphidius rhopalosiphi, to volatile chemical cues from the host plants of their prey. Physiol. Entomol. 17: 297-304.

Xia S.-Z., Feng C.-H. \& Guo A.-K. 1999: Temporary amnesia induced by cold anesthesia and hypoxia in Drosophila. Physiol. Behav. 65: 617-623.

Received October 23, 2007; revised and accepted March 13, 2008 